\title{
Manipulation of soil biota in ecological research
}

\author{
Wei-Ming He and Qing-Guo Cui
}

He, W.-M. and Cui, Q.-G. 2009. Manipulation of soil biota in ecological research. Web Ecol. 9: 68-71.

\begin{abstract}
Manipulation of soil biota, such as soil sterilization, may have complex effects as they alter soil properties as well as microorganism communities. To assess the effects of such manipulation, we conducted an experiment using three sterilizing approaches, two soil types, and two plant species to identify the problems that may occur when different sterilizing approaches are used. The sterilizing treatments decreased growth of plants and resulted in large changes in soil nutrients and $\mathrm{pH}$. Such effects varied with the approach followed. Our data suggest that studied effects on soil biota may be misleading if we fail to consider such changes in the soil.
\end{abstract}

W.-M. He (weiminghe@ibcas.ac.cn) and Q.-G. Cui, State Key Lab of Vegetation and Environmental Change, Inst. of Botany, Chinese Academy of Sciences, CN-100093 Beijing, China.

Soil microorganisms interact with plants via mutualisms, nutrient cycling and uptake (van der Heijden et al. 1998, Klironomos 2002, Callaway et al. 2004, Bennett and Bever 2007), but may affect plants through competition for resources (Reinhart et al. 2005, Reinhart and Callaway 2006). The importance of soil microorganisms has received increasing attention, particularly regarding invasion ecology (Powlson and Jenkinson 1976, Wolf et al. 1989, Alphei and Scheu 1993, Bever 2002, Jackson et al. 2007, van der Heijden et al. 2008).

One tool often used in such studies is soil sterilization, which may identify the importance of soil microorganisms in ecological processes and patterns (Callaway et al. 2001, Ayres et al. 2004, Bennett and Bever 2007). However, different sterilizing approaches have contrasting influences on soil biota and soil properties (Powlson and Jenkinson 1976, Wolf et al. 1989, Alphei and Scheu 1993, Troelstra et al. 2001). Although soil biota may play important roles in plant community assemblages, such importance may be misled due to a failure to recognize the compound sterilization effects. However, little effort has been made to examine this issue under the context of plant communities. We present here a case study, where we identify problems that may occur with different sterilizing treatments.

\section{Methods}

In 2006 we collected soil samples from depths of $0-20 \mathrm{~cm}$ beneath Dodonaea viscosa thickets, as well as from thicket gaps. Dodonaea viscosa is one of the dominant native species. The control soils were kept intact, and the 'experimental soils' were treated either by autoclaving $\left(120^{\circ} \mathrm{C}\right.$ for $1 \mathrm{~h}$ on three consecutive days), by applying a fungicide (Benomyl), or by gamma radiation. Soils were then transferred into $1000 \mathrm{~cm}^{3}$ pots ( 4 treatments $\times 9$ replicates $\times 2$ soils $\times 2$ species $=144$ ). Prior to and after sterilization, we took samples from each soil to determine available nitrogen $(\mathrm{N})$, phosphorus $(\mathrm{P})$, potassium $(\mathrm{K})$, and $\mathrm{pH}$. There were five replicates for soil analyses.

We conducted an experiment using Bidens pilosa and Gynura spp. as phytometers. These two species are dominant invasive plants in sub-tropical southwestern China. All plants were grown from seeds, and pots were supplied $50 \mathrm{ml}$ of water at 1-2 dintervals for 10 weeks. At the end of the experiment, all plants were harvested, dried and then weighed. There were nine replicates for plant biomass. We used analysis of variance (ANOVA) (SPSS 13.0) to test for sterilization effects and to compare soil properties and biomass among treatments. 

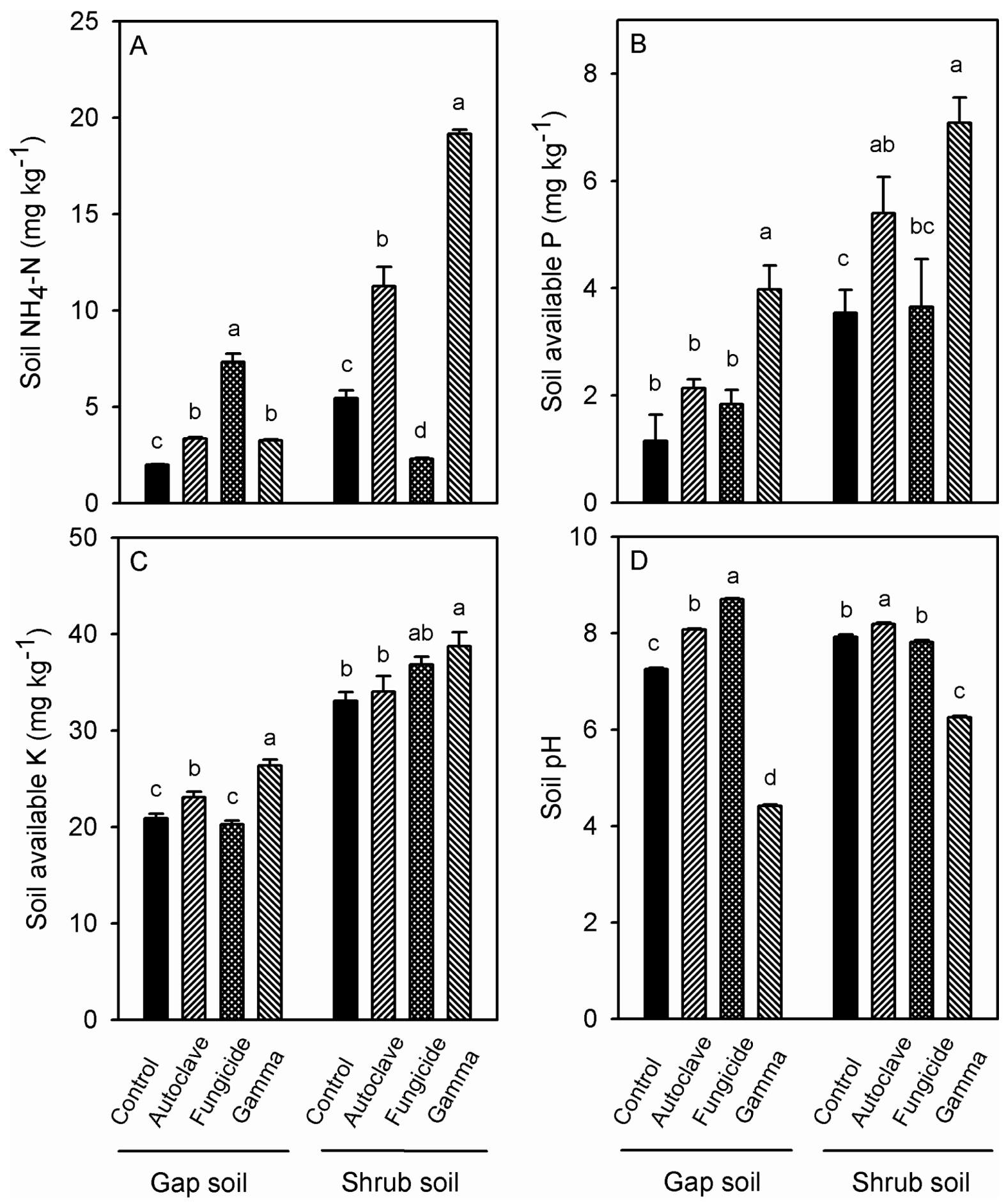

Figure 1. Changes in soil $\mathrm{NH}_{4}-\mathrm{N}(\mathrm{A})$, soil available $\mathrm{P}(\mathrm{B})$, soil available $\mathrm{K}(\mathrm{C})$, and soil $\mathrm{pH}(\mathrm{D})$ with different biocidal treatments. Data are means $+1 \mathrm{SE}(\mathrm{n}=5)$. Different letters within a soil type indicate statistically significant differences $(\mathrm{p}<0.05)$ among treatments. 


\section{Results and discussion}

We present the absolute values of each soil treatment. $\mathrm{NH}_{4}-\mathrm{N}$ dramatically responded to sterilization $(\mathrm{p}<0.001)$; three approaches increased soil $\mathrm{NH}_{4}-\mathrm{N}$, with an exception for shrub soil with fungicide (Fig. 1A). Compared to the control, autoclaving enhanced $\mathrm{P}$ in shrub soil and $\mathrm{K}$ in gap soil $(\mathrm{p}<0.05)$. Fungicide had no effects on $\mathrm{P}$ and $\mathrm{K}$ in either type of soil (all $p>0.05$ ), and gamma radiation increased $\mathrm{P}$ and $\mathrm{K}$ in gap and shrub soil $(\mathrm{p}<0.05)$ (Fig. $1 \mathrm{~B}, 1 \mathrm{C})$. Relative to the control, autoclaving increased $\mathrm{pH}$ in gap and shrub soils $(\mathrm{p}<0.05)$, whereas fungicide increased $\mathrm{pH}$ in gap soil, but not shrub soil, and lastly, gamma-irradiation decreased $\mathrm{pH}$ in two types of soils $(\mathrm{p}<$ 0.001) (Fig. 1D).

The decreased biomass of Bidens pilosa showed different responses to autoclaving, fungicide, and gamma radiation $(\mathrm{F}=7.891, \mathrm{p}=0.004$ for gap soil; $\mathrm{F}=5.069, \mathrm{p}=0.015$ for shrub soil); however, the decreased biomass of Gynura spp. exhibited similar responses to all three approaches $(\mathrm{F}$ $=1.156, \mathrm{p}=0.340$ for gap soil; $\mathrm{F}=1.469, \mathrm{p}=0.254$ for shrub soil) (Fig. 2).

Three sterilizing approaches did cause large nutrient flushes (Fig. 1). These data agree with previous results that different sterilizing approaches have contrasting effects on soil properties (Powlson and Jenkinson 1976, Troel- stra et al. 2001). Troelstra et al. (2001) pointed out that sterilization results in nutrient flushes due to the killing of microbes. Another explanation is that sterilization may decrease plant growth, which in turn decreases nutrient uptake by plants. Troelstra et al. (2001) proposed a set of conventions to resolve such nutrient flushes: treated soils (sterile vs non-sterile) are deliberately set to represent relatively small fractions of the total soil volume. Another way to prohibit nutrient flushes is to fertilize the pots to dilute potential chemical differences between pots. However, it is really difficult to exclude sterilization-induced changes in soil properties technically. The impacts of increased nutrient availability after sterilization can be reduced by soil leaching (Heath et al. 2005). In addition, there are dozens of fungicides which most likely have varying direct and indirect effects.

Our three sterilizing approaches decreased production in the two plant species (Fig. 2). This decrease is linked to at least two aspects; that is, effects on soil biota and changes in soil properties. In other words, any change in plant performance cannot be simply be ascribed to soil biota or soil properties. It is these aspects that jointly shape apparent responses of plants to sterilizing approaches. Given that soil biota and soil nutrients are key drivers for plant community assemblage (Blumenthal 2005, Wolfe and Klironomos 2005, Reinhart and Callaway 2006), it is
Bidens pilosa

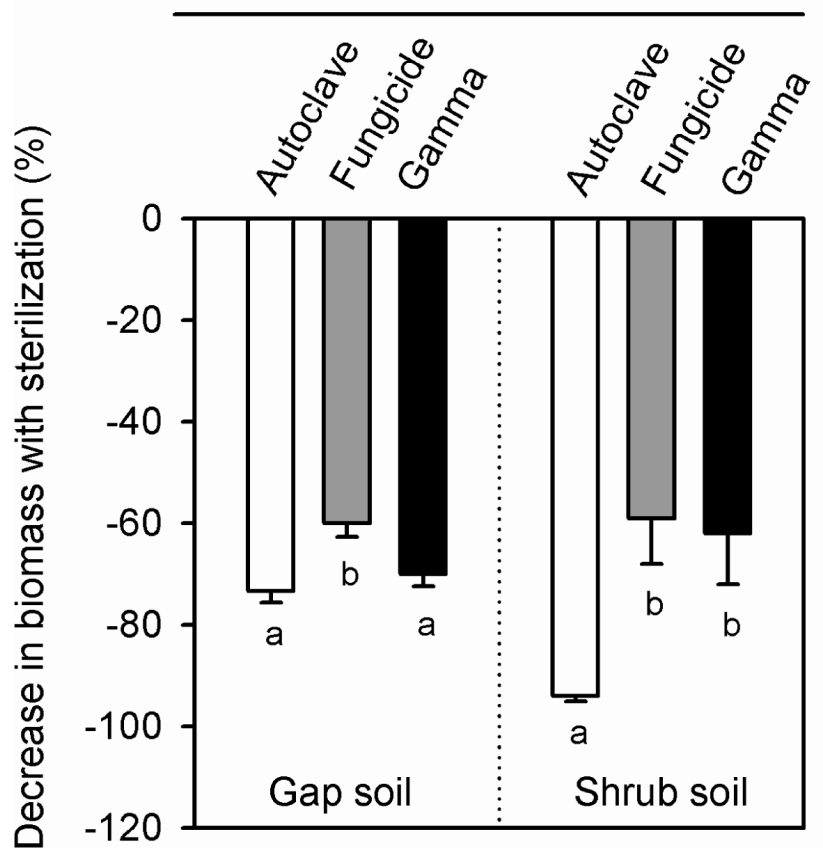

Gynura spp.

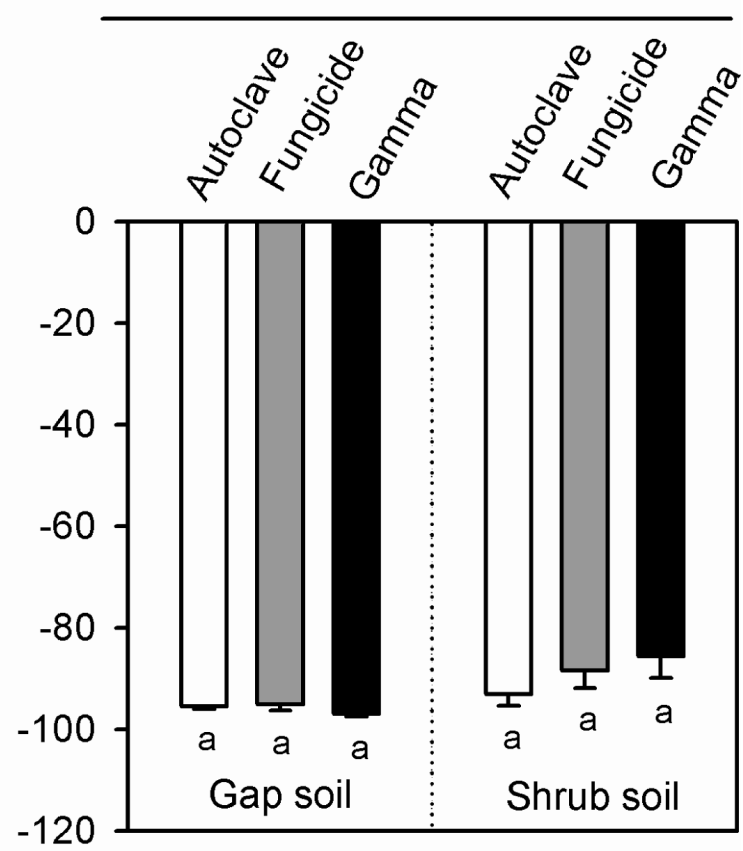

Figure 2. Decrease in total biomass with biocides in Bidens pilosa and Gynura spp. Data are means $+1 \mathrm{SE}(\mathrm{n}=9)$. The decrease in total biomass was calculated according to the following equation: $\left(M_{s}-M_{c}\right) / M_{c} \times 100 \%$, where $M_{s}$ is the total biomass of plants under sterilized conditions and $\mathrm{M}_{\mathrm{c}}$ is the total biomass of plants in the control. Different letters within a soil type indicate statistically significant differences $(\mathrm{p}<0.05)$ among biocidal treatments. 
necessary to identify their relative strengths. Fertilization experiments are required to quantify the relative importance of nutrient availability. Knowledge of the net effects of soil biota is useful for understanding their roles in community dynamics (Wolfe and Klironomos 2005). However, sometimes sterilizing approaches likely mislead the strengths of soil microbes due to the failure to consider altered soil properties, particularly nutrient flushes. Thus, it is necessary to single out appropriate approaches when analyzing related data, thereby assigning a more appropriate importance to each factor.

Additionally, we should be more careful when synthesizing data. First, plant performance and soil properties exhibit different responses to different sterilizing approaches. In our study, fungicide conferred the lowest influences on plant performance and soil properties. Compared to autoclaving, gamma-irradiation had greater effects on soil properties and less influence on plant growth. Second, the sterilization effects may depend on soil nature. For example, the same sterilization treatment had contrasting impacts on plant performance and soil properties, and fungicide increased $\mathrm{NH}_{4}-\mathrm{N}$ in gap soil but decreased $\mathrm{NH}_{4}-\mathrm{N}$ in shrub soil. Finally, differences exist in sterilization response among species. Autoclaving, fungicide and gamma-irradiation had different effects on the growth of B. pilosa; in contrast, these treatments had similar effects on the growth of Gynura spp. In other words, the consequences of sterilization can vary with sterilizing approaches, soils, and species.

\section{References}

Alphei, J. and Scheu, S. 1993. Effects of biocidal treatments on biological and nutritional properties of a mull-structured woodland soil. - Geoderma 56: 435-448.

Ayres, E. et al. 2004. Tree physiological responses to aboveground herbivory directly modify below-ground processes of soil carbon and nitrogen cycling. - Ecol. Lett. 7: 469-479.

Bennett, A. E. and Bever, J. D. 2007. Mycorrhizal species differentially alter growth and response to herbivory. - Ecology 88: 210-218.
Bever, J. D. 2002. Negative feedback within a mutualism: hostspecific growth of mycorrhizal fungi reduces plant benefit. - Proc. R. Soc. Lond. B 269: 2595-2601.

Blumenthal, D. 2005. Interrelated causes for plant invasion. Science 310: 243-244.

Callaway, R. M. et al. 2001. Compensatory growth and competitive ability of an invasive weed are enhanced by soil fungi and native neighbors. - Ecol. Lett. 4: 1-5.

Callaway, R. M. et al. 2004. Soil biota and exotic plant invasion. - Nature 427: 731-733.

Heath, J. et al. 2005. Rising atmospheric $\mathrm{CO}_{2}$ reduces sequestration of root-derived soil carbon. - Science 309: 17111713 .

Jackson, R. B. et al. 2007. New directions in microbial ecology. - Ecology 88: 1343-1344.

Klironomos, J. N. 2002. Feedback with soil biota contributes to plant rarity and invasiveness in communities. - Nature 417: 67-70.

Powlson, D. S. and Jenkinson, D. S. 1976. The effects of biocidal treatments on metabolism in soil - II gamma irradiation, autoclaving, air-drying and fumigation. - Soil Biol. Biochem. 8: 179-188.

Reinhart, K. O. and Callaway, R. M. 2006. Soil biota and invasive plants. - New Phytol. 170: 445-457.

Reinhart, K. O. et al. 2005. Soil feedback and pathogen activity in Prunus serotina throughout its native range. - J. Ecol. 93: 890-898.

Troelstra, S. R. et al. 2001. Interpretation of bioassays in the study of interactions between soil organisms and plants: involvement of nutrient factors. - New Phytol. 150: 697-706.

van der Heijden, M. G. A. et al. 1998. Mycorrhizal fungal diversity determines plant biodiversity, ecosystem variability and productivity. - Nature 396: 69-72.

van der Heijden, M. G. A. 2008. The unseen majority: soil microbes as drivers of plant diversity and productivity in terrestrial ecosystems. - Ecol. Lett. 11: 296-310.

Wolf, D. C. et al. 1989. Influence of sterilization methods on selected soil microbiological, physical, and chemical properties. - J. Environ. Qual. 18: 39-44.

Wolfe, B. E. and Klironomos, J. N. 2005. Breaking new ground: soil communities and exotic plant invasion. - BioScience 55 477-687. 